\title{
Construction of TCM English Intelligent learning system in the Era of Internet +
}

\author{
Yanxia $\mathrm{Wu}^{1}$ and Weicai Song ${ }^{2}$ \\ ${ }^{1}$ Institute of humanities, Jiangxi University of Traditional Chinese Medicine, Nan chang,330004, China \\ ${ }^{2}$ Institute of Computer Science, Jiangxi University of Traditional Chinese Medicine, Nan chang, 330004, China
}

\begin{abstract}
At present, the teaching materials of TCM (Traditional Chinese Medicine) English which learners can choose are limited and which some important updated information about TCM are not provided timely in. A platform of resources and communication is urgently needed to provide high quality service for TCM English learners. The advent of the era of "Internet + " brings opportunities and challenges to the development of TCM English education. Driven by the trend of "Internet +", we try to establish TCM English Intelligent learning system which will conform to the trend of "Internet + " in ecological environment, resource supply, system design to accelerate the pace of TCM English education modernization.
\end{abstract}

\section{Introduction}

On March 5, 2015, Chinese prime minister, Li Keqiang, in the Report on the Work of the Government put forward the concept of "Internet + "for the first time $([1,2])$. The potential meaning of "Internet +" can be interpreted by means of a formula," Internet + ?=?". In this formula, nothing more than one factor is clear, that is the "Internet", and other factors can be freely imaged. When internet + traditional market, Taobao, the largest and most popular Internet site, appeared; When internet + traditional Banks, Alipay, a Web payment processing service founded by Alibaba Group, appeared; When internet + mobile phone, WeChat appeared...... $([3,4,5])$ Driven by the trend of "Internet +", the TCM English education will establish "Internet + TCM English" running mechanism and construct TCM English intelligent learning system. With the deep fusion of the internet

Innovation and the TCM English teaching, the teaching activities will typify the internet characteristics of "personalized, mobile, social, digital". There by at the present and the future, our TCM English teaching team will multiply our efforts to make the following preparations for the TCM English Intelligent learning system:

\section{The ecological environment}

Although teachers were trained in information technology in the past few decades time and time again, but the teaching style in the classroom merely took on a small range change, in which we diminutively employed the PPT in the place of the traditional blackboard writing. It seems the impact of internet development on education is not enough to fundamentally change the ecological environment of the education. Therefore actions might as well be taken. Firstly we are supposed to establish the ecological environment of TCM English learning with an advanced education thoughts as the instruction; Secondly we should build the pleasant learning environment of free exchange, discussion, collaboration rather than the teaching process; Finally we will promote the sharing and evolution of the knowledge and develop students' ability.

\section{Resource supply}

\subsection{Co-construction of the teachers and students}

Against the network background knowledge is ceaselessly fused, updated and expanded. The complexity of the knowledge is intensified and the available resources is luxuriant, but there is a knowledge mingling of good and evil. In such cases, the filtering and sorting of knowledge is particularly important. The construction of TCM English intelligent learning system adheres to the following principles: Co-construction of the teachers and students. Teachers design system framework, students design creative work. In other words, teachers cultivate creative students and student produce creative works. Give full play to the collective ability and form into the collective wisdom.

\subsection{Balance the form and the content}

To avoid the problem of paying more attention to the form and less attention to content, the pattern of "Internet + TCM English" innovate not only the forms, but also the teaching content that are conveyed by the forms. The 
students personally arrange and iterate the personalized learning contents based on the learning condition, interests, and methods, and teachers carry on the teaching design and targeted training based on students' learning records on the system so that a pointed practice can be provided.

\subsection{Match the practice with the theory}

TCM English learning in Intelligent learning system is synchronized with the solution of the problem. We are prepared to distribute the assignment, completing creative works, to students from the beginning, which will drive students to learn by doing. Whereby we will transform the obsolete method of the acquiring the knowledge into the superior methods of the applying the knowledge. TCM English online learning system provides the theoretical knowledge and practical field, render students to connect the knowledge with the real world, and upgrade learning from knowledge continuity to knowledge creation.

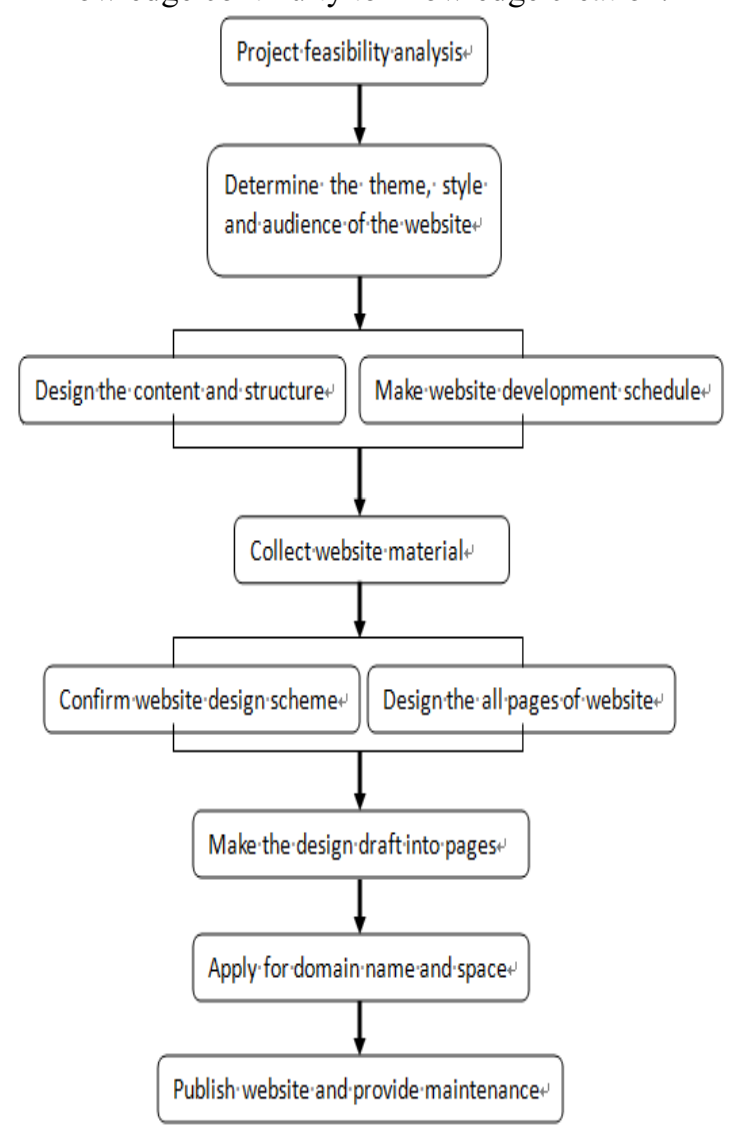

Figure1. Development process of the system

\section{The design of the system}

\subsection{Design orientation of TCM English Intelligent learning system}

We have to determine the system design orientation before the design of TCM English Intelligent learning system. Put simply, it is to determine the theme and the style of the system according to audience, subject characteristics and teaching law. The determination of the theme and the style is precondition of the design and production. Theme of the system is the details that the viewers browse from the system. The style of the system is this specific content to show the details. The former is the core of the system production, the direction of system development, and the latter is the manifestation of this specific content. Establishing superior system depends on a fine theme. Setting up your style, mainly decides two aspects: the visual effect and the functional content of the system.

\subsection{Constructive process of TCM English Intelligent learning system}

The system design the static website by virtue of Photoshop + Dreamweaver + Flash and achieve dynamic development of interactive features by means of IIS + SQL server + Asp.net. The development process is shown in Fig. 1.

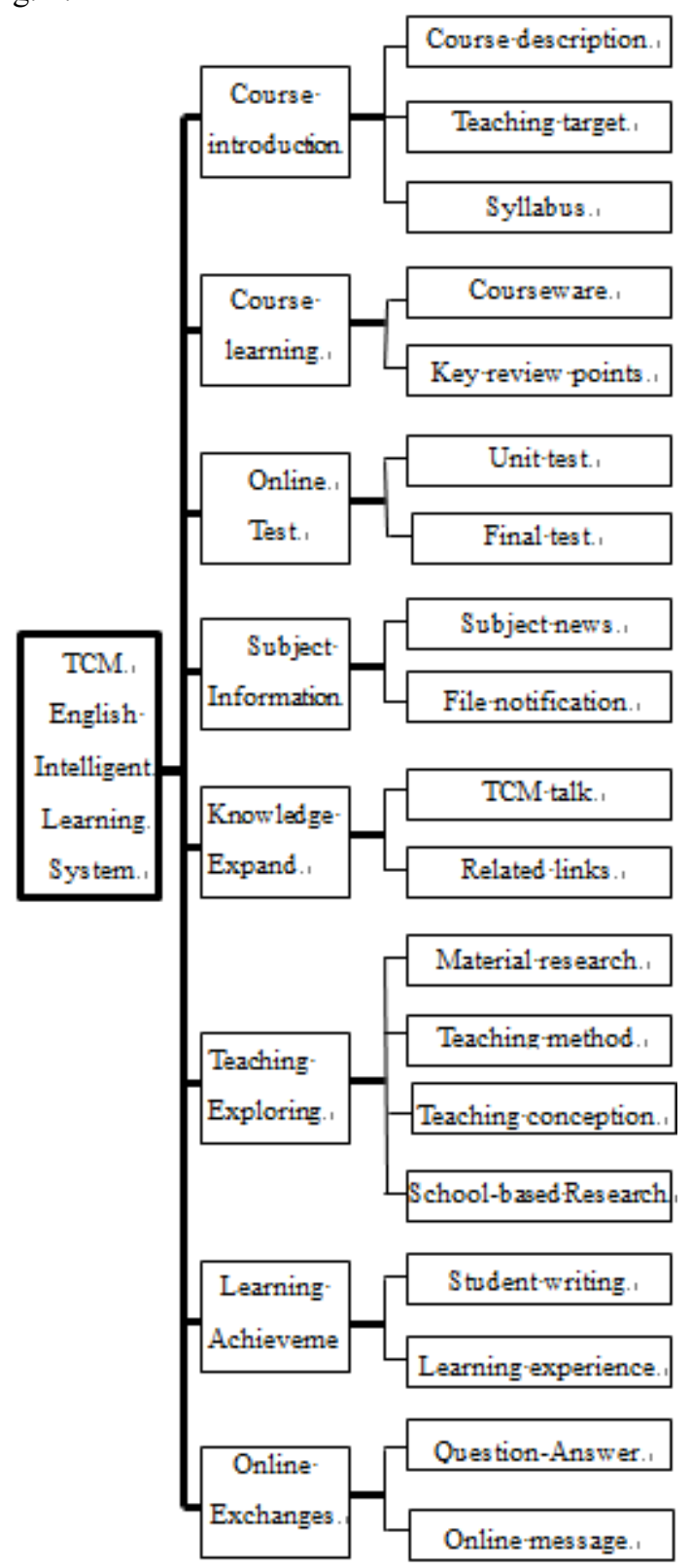

Figure 2. Function modules of the system 


\subsection{Function modules of TCM English learning system}

As for an excellent learning system, its knowledge structure should be complete and comprehensive, and its presentation should be switchable and flexible. Content focus should be put on the knowledge navigation, providing learners with the knowledge structure of the entire website at any time so that students always know which part of the knowledge structure what they are currently studying is located on and know the contextual content ([6], [7]). Thus the learners will not get lost in the vast ocean of knowledge. Based on design orientation of TCM English learning system, the system is divided into such eight functional modules as course descriptions, course learning, online testing and others in terms of the function module setting, shown in Fig. 2 and Table 1:

Table 1. Function module pages

\begin{tabular}{|c|c|}
\hline System modules & System module pages \\
\hline Course Homepage & Index.aspx \\
\hline Course Introduction & Introduction.aspx \\
\hline Course Learning & Learning.aspx \\
\hline Online Testing & Test.aspx \\
\hline Subject Information & Information.aspx \\
\hline Knowledge Expand & Knowledge.aspx \\
\hline Teaching Exploring & Explore.aspx \\
\hline Learning Achievement & Achievement.aspx \\
\hline Online Exchanges & Exchange.aspx \\
\hline
\end{tabular}

SQL server2008 database is used here. Based on the design of the database concept and the analysis of the system function module, two main databases are designed: the database of Users' information and the database of Administrators' information ([8]). The data sheets are designed as following Table 2 and Table 3.

Table 2. Users' information

\begin{tabular}{|c|l|c|l|}
\hline Column Names & Data Types & $\begin{array}{l}\text { Field } \\
\text { Length }\end{array}$ & $\begin{array}{l}\text { Null/ } \\
\text { Not Null }\end{array}$ \\
\hline ID & char & 8 & Not null \\
\hline User Name & varchar & 10 & Not null \\
\hline Password & char & 9 & Not null \\
\hline Sex & char & 2 & Not null \\
\hline Birthday & Date time & 8 & Not null \\
\hline School and Specialty & varchar & 40 & Not null \\
\hline E-mailln Campus & varchar & 20 & Not null \\
\hline
\end{tabular}

Table 3. Administrators' information

\begin{tabular}{|l|l|l|l|}
\hline Column Names & $\begin{array}{l}\text { Data } \\
\text { Types }\end{array}$ & $\begin{array}{l}\text { Field } \\
\text { Length }\end{array}$ & $\begin{array}{l}\text { Null/ } \\
\text { Not Null }\end{array}$ \\
\hline ID & char & 8 & Not null \\
\hline AdminClass & varchar & 10 & Not null \\
\hline AdminUserID & varchar & 8 & Not null \\
\hline
\end{tabular}

\section{The application of system}

When completed, system will bring forth a lot of teaching innovation.

\subsection{Innovation of the teaching application}

Based on the TCM English Intelligent learning system we will set up new teaching. Pay special attention to the deep integration of digital resources and teaching and give full play to the advantage of the system's convenience and quick in order to promote the efficiency of TCM English teaching. Relying on the HD recorded classroom, we will start course-lecturing and course-competing activity to build the high-quality class. Actively carry out sapiential classroom teaching pilot and flip classroom teaching research, explore effective ways of students' autonomous learning against the network environment, promote the teaching reform, study the teaching mode based on large data analysis and strengthen the pertinence and effectiveness of teaching. Give full play to the role of TCM intelligent learning system, share education and teacher resources, actively carry out intercollegiate exchange and research and obtain complementary advantages and win-win cooperation.

\subsection{Innovation of the learning ways}

Based on the TCM English Intelligent learning system we will set up students' learning mode. Through QQ or WeChat group we will push learning content and surrounding the topic we will carry out learning exchange activities once a month, guiding students to learn spontaneously and lightheartedly.

By means of reading together on the system, we start such activities as "reading classic and current affairs", "establishing reading database on the system", "timely delivering articles and bibliography" to expand the space-time of the students' learning. Relying on online communication, we proceed learning communication, task arrangement, the online FAQ, inquiry learning and the like to promote interaction between teachers and students, and between students and students to ensure that students can preview before class and review after class. Guide students to use mobile terminals to carry out autonomous learning, cooperative learning, network learning and boost net learning become a habit.

\subsection{Innovation of the student assessment}

Based on the TCM English Intelligent learning system we will set up student evaluation mechanism. In virtue of the evaluation system on digital system which will assess students' comprehensive quality. We will construct the scientific student evaluation mechanism to meet the following intentions: digital evaluation means, diversified evaluation subject and scientific evaluation content. We will negotiate actively to expand the digital evaluation function and open the evaluation way of the mobile version in order to make the evaluation process more convenient, quick, and timely, assisting students to make 
scientific evaluation and judgment about their development and providing scientific basis for the students' long-term development $\mathrm{p}$.

\section{Conclusion}

The advent of the era of "Internet + education" brings opportunities and challenges to the development of TCM English. Thereby we should seize opportunities and think calmly. Primarily we should adhere to the "Education is the core, and the Internet is the tool". No matter how technology develops, we should always bear in mind that education is the core target, and the Internet is the tool that is merely used to improve and change education technology and that is supposed to used reasonably. Secondly TCM English education should dare to shift from the knowledge education to the thinking education. In the face of the impact of the "Internet +", the TCM English education take more responsibility to "teach them the fishing", giving priority to the concise rather than fussy know ledge and transforming the knowledge-oriental education to thinking-oriental one.

\section{References}

1. 2015 the Report on the Work of the Government[EB/OL].http://www.people.com.cn/n/

2. Guiding opinions of the State Council on promoting "Internet+" action. [EB/OL].

3. http://news.xinhuanet.com/politics/201507/04/c_1115815944.htm.,2015-7-4.

4. W. Cai, "Education Reform in the era of "Internet +". China Education Newspaper, 4 (2015)

5. A. G. Tang, G. Yang, Study on the Construction of University Online Teaching System against "Internet +". Computer Knowledge and Technology, 11( 2015)

6. X. H. Zhu, Promote the Modernization of Education via "Internet +". Xuezhoukan, 5 (2016)

7. X. K. Wang, L. L. Liu, ASP.NET Full Record of Atypical Module Development. Beijing: Tsinghua University Press, (2010)

8. Y. Yang, Y. X. Zhang, Chinese Version of Dreamweaver + Flash + Photoshop Web Production: from Entry to the Master. Beijing: Tsinghua University Press, (2010)

9. L. Wei, SQL Server 2008 Database application and development course. Beijing: Tsinghua University Press, (2011) 